\title{
Kill to Save or Save to Kill: Assessing Ethical Principles on Eradication of Invasive Pterois Volitans and Pterois Miles (Lionfish) in South East Coast of United States and Caribbean Region
}

\author{
Ahyana Maxine Bowen ${ }^{1}$, Firmin Fangnon Fangninou ${ }^{2}$, Ithabeleng Anna Moleli ${ }^{3}$, Rejoice Mwamba ${ }^{4}$ \\ ${ }^{1}$ College of Environmental Science and Engineering, Tongji University, 1239 Siping Road, Shanghai 200092, P.R. China
}

\begin{abstract}
The Pterois volitans (red lionfish) and Pterois miles (devil firefish) invasion poses unprecedented threat to biodiversity. The invasive lionfish has become an impending threat to native fish communities, human health, and fisheries resources. The specie has caused extensive impacts, harming native ecosystems in its new habitat waters of US south east coast and Caribbean coastal water. Their role in the food chain still remains vague as their dietary habits are unbiased and generally difficult to predict. The fish have been found to rapidly increase in population size and at present densities exceed those of all but the most common predatory fish species on many reefs in the Caribbean and off of South East United States (SEUS) coast. Various literature reviewed reveals that the impacts of the fish on the ecosystem would potentially result in a future marred with biodiversity loss. The invasive lionfish are out-breeding, out-competing and out-living native fish stocks and other marine species. The consequences impact the food security and economies affecting over a hundred million people. Application of ethical principles to finding a mitigatory stance for the problem at hand becomes key. This paper presents two theories, ecocentrism and biocentrism to aid rational approach and decision. Furthermore, our moral duty as humans to the environment prompts us to consciously decide on natures' and our own behalf that the invasive fish specie be depopulated through 'killing'. This would help the dwindling native species population to increase and would overall have equated ecological and economic benefits.
\end{abstract}

Keywords: ecocentrism, biocentrism, lion fish, devil firefish, pteroisvolitans, invasive species, mitigation, biodiversity, native

\section{Introduction}

Biological invasions are a major driver of global change, and a number of invasive species alter key ecological feedbacks in ways that lead to regime shifts, with consequences for biodiversity, ecosystem services, livelihoods and human wellbeing (Shackleton, Ross T., et al, 2018). There has been rising concerns on the impacts of invasive species on ecosystems. Various scholars on the subject have noted that "some invasive species cause rapid, substantial and long-lasting changes to the structure and function of ecosystems - so-called regime shifts - that are very difficult or impossible to reverse (Scheffer et al., 2001; Gaertner et al., 2014; Hui and Richardson, 2017 qtd in Shackleton, Ross T., et al, 2018). Such shifts have major implications for biodiversity and can cause extinctions and large-scale community change. The shifts can also substantially alter or change the supply of ecosystem services, thereby having significant impacts on human wellbeing and livelihoods, through their effect on factors such as human health and agricultural productivity (see, Shackleton et al., 2007, 2018a). One such biological invasive specie that has caught world attention is the Pterois volitans and Pterois miles. And according to Bos et. al, (2018), The introduction of lionfish into the western Atlantic and Caribbean Sea is widely recognized as the most successful marine fish invasion documented to date. The lion fish invasion can be traced back to the period between 1980 s and early 1990 s. it has been said that the first lionfish was reported in South Florida waters in 1985 with many additional sightings occurring until they were documented as established in the early 2000s.

The Pterois volitans (red lionfish) and Pterois miles (devil firefish) is a longstanding showstopper in home aquariums, is a flourishing invasive species in U.S. Southeast and Caribbean coastal waters. The fish is called by common names including lion fish, zebrafish, firefish, turkeyfish, red lionfish, butterfly cod, ornate butterfly-cod, peacock lionfish, red firefish, scorpion volitans and devil firefish. The species are volitans, that is to say, they are volatile or poisonous. Lionfish are now one of the top predators in many coral reef environments of the Atlantic and consume over 50 species of native fishes including some economically and ecologically important species such as groupers and parrotfishes. Their dominance is reinforced by the fact that they maintain a high level of vigilance while hunting and stalk their prey with apparent impunity. Lionfish demonstrate a suite of predatory characteristics and behaviors that native prey have not encountered in their evolutionary history (Albins\& Hixon, 2013). The fish can live from five to 15 years and have complex courtship and mating behaviors (Ruiz-Carus et. Al 2006). Due to the fact that they have no known predators, this entails rapidness in the increase of their population. The population increase is also attributed to their reproduction; they reproduce all year long, Females release two mucus-filled egg clusters frequently, which can contain as many as 15,000 eggs (Carus et. al 2006).

\section{Analytical Methods}

The philosophical assertion that all things have inherent value is known as eco-centrism. This theory asserts that every organism in nature must be viewed for its intrinsic value and not its instrumental value. Eco-centrism says, for example, that the value or worth of a tree or flower is not 


\section{International Journal of Science and Research (IJSR) ISSN: 2319-7064}

ResearchGate Impact Factor (2018): 0.28 | SJIF (2018): 7.426

judged simply by the ways that humans can use it. Instead, it is valuable because it plays a role in the greater environment. It does not believe in exploitation of nature simply for human benefit. This means that humans have to respect the environment for its own sake and do not justify harmful practices by claiming their importance or benefits to humans. There is also the theory of biocentrism which states that all living things have inherent value. Living things compose ecosystems, mutually supportive systems of life, in which each thing plays an important role. Therefore, a tree and a human would be of equal inherent value, but both would be more morally valuable than a rock or water. Living things matter more, and our moral obligations extend to protecting the living parts of nature over the non-living parts.

The question of the value of the environment; whether its value is assigned by us humans according to its materialistic worth, or maybe by its place in our culture or through the different ways we can utilize it, or perhaps the environment is at the foundation of our philosophical debates about the environment and ecosystem. The theory of eco-centrism therefore justifies our use of the environment to preserve and better our lives. According to this theory, if we are to protect the environment and ecosystems from the harmful and severely invasive species, it would be morally correct to kill them in order to protect the coastal reef of the Caribbean and to mitigate negative effects on the ecosystem and the economy. Lionfish reproduction is very high therefore, if they are killed they would still be able to multiply which means they cannot be totally destroyed (CarballoCárdenas, E. C. 2015) and the world population of the species and the survival of the species would be unaffected.

Management and prevention of anything detrimental to the ecosystem is very crucial. The ethical dilemma under scrutiny here can be subsumed through many ethical principles as seen in Figure 3 which shows "Conceptualizations of nature and implications for non-native species management" (based on Callicott et al. 1999 and Keulartz and van der Weele 2008) in Ecology and society.

\section{Results and Discussion}

Indo-Pacific lionfish, Pterois volitans and Pterois miles is native to the Indian Ocean: Persian Gulf and Red Sea south to Port Alfred, South Africa and east to Sumatra, Indonesia (Turan). The Lionfish can reach up to $38.0 \mathrm{~cm}$ in length and found in stripped reddish to tan or grey color. The head and body are covered in bars, spines are banded on the cheek and a faintly banded tentacle grows above the eye; in total species has 13 dorsal spines; 9-11 dorsal soft rays; 3 anal spines; and 6-7 anal soft rays. The highly venomous lionfish species dwells in tropical marine reefs of depth range $25-85 \mathrm{~m}$ (Kuiter). Upon attack of a human the venom causes excruciating pain for which no treatment or antidote exists, and the long-term disability caused by the pain is concern ((Mouchbahani-Constance, Lesperance et al. 2018).

Known to be native to South Pacific and Indian Oceans (i.e., the Indo-Pacific region). The range of the lionfish covers a very large area from western Australia and Malaysia east to French Polynesia and the United Kingdom's Pitcairn Islands, north to southern Japan and southern Korea and south to Lord Howe Island off the east coast of Australia and the Kermadec Islands of New Zealand. In between, the species is found throughout Micronesia. The Indo-Pacific lionfishes are the first nonnative marine fishes to establish in the Western North Atlantic/Caribbean region (Schofield, 2010). According to (Morris, James and Whitfield, 2009) the Venomous Indo-Pacific lionfish (Pterois miles and P. volitans) are now established along the Southeast U.S.A. and parts of the Caribbean and pose a serious threat to reef fish communities of these regions. It still remains speculative how the fish found its way into the southeast and Caribbean coastal waters. Their presence may be attributed to aquarium discharge, according to Arndt et. al, (2018) aquarium trade is considered another important anthropogenic vector with regard to Non-Indigenous Fish (NIF), because a large number of new NIF records in the last 20 years are likely related to aquarium releases. However, in most cases this introduction pathway has not been verified, as it is not known whether the species in question were released singularly or multiple times, or if breeding populations have established successfully. Nevertheless, the wildly successful invasion of the lionfishes, Pterois miles (Bennett, 1828) and P. volitans (L., 1758) along the south-east coast of the US and in the Greater Caribbean is due to an aquarium release (Semmens et al., 2004; Schofield, 2009) and has produced one of the largest impacts of any invasive marine fish to date (Benkwitt, 2015).

In its native range the lionfish can be found over coral, sand and hard bottom substrate from the surface to $50 \mathrm{~m}$ (Carus et. at, 2006). Lionfish can live in a huge range of water quality, salinity, temperature and depth with relatively no stress. For instance, they have been spotted in water as little as 1 foot (.3m) deep to beyond 1,000 feet $(305 \mathrm{~m})$ deep, in brackish water river estuaries and mangroves, where most of the juvenile fish grow up. Being able to tolerate water temperatures down to 50 degrees Fahrenheit (10 degrees Celsius). This fish are highly tolerant to temperature change

The above figure shows the extent of lionfish invasion of the US south east coast and Caribbean coastal water invasion. The vast invasion can be used to tell the growing severity of continued invasion. A review of the population trend by Ballew, Nicholas G., et al. "Invasive lionfish reduce native fish abundance on a regional scale." Scientific reports 6 (2016): 32169, reveals that the first assessment of lionfish densities in their non-native range, which was conducted in 2004, reported an average of 21 lionfish across 17 locations off North Carolina. By 2008, the maximum lionfish densities observed off North Carolina were approximately 450 lionfish, with mean densities of about 150 lionfish per hectare. Today, lionfish densities exceed those of all but the most common predatory fish species on many reefs in the Caribbean and off of the SEUS (Albins). Lionfish could be reducing Atlantic reef diversity by up to $80 \%$ (Myers).

Impacts of new predatorial species may be extensive resulting in loss of native species which may throw the 


\section{International Journal of Science and Research (IJSR) ISSN: 2319-7064}

ResearchGate Impact Factor (2018): 0.28 | SJIF (2018): 7.426

ecosystem off balance. For example, the introduction of Nile perch to Lake Victoria, a system which previously lacked a large pike-like predator, resulted in the extinction of more than 100 species of native fish. In a terrestrial example, the brown tree snake has extirpated or drastically reduced populations of 17 of 18 native birds on Guam, an island which was entirely free from snakes previous to its introduction (Ogutu-Ohwayo1990; Wiles et al. 2003 qtd in Albins, 2015). As predators, lion fish reduce the recruitment of young and native fishes, this can disrupt the biodiversity of the reef and lead to disruption of the marine ecosystem process. And according to Lionfish could be reducing Atlantic reef diversity by up to $80 \%$ (Myers, 1991).

Lion fish also have socio-economic impacts. Most Caribbean islands like Jamaica according to (WRI 2005) are particularly vulnerable to biological invasions because their economies display intensive use of natural resources for domestic livelihoods. For instance, Jamaica's Fisheries contributes approximately $0.4 \%$ to its total Gross Domestic Product (GDP) and affects the livelihood of approximately 13,000 persons. And provided that outcompetes and preys on the native commercial species the impacts will directly translate into an economic impact to Jamaica's fishing industry and a cost to its economy. The lionfish poses a serious threat to the general public, as well as those who encounter lionfish on a daily basis (Ruiz-Carus et al., 2006), the situation likely to worsen with population increase. This is because the fish contains venom glands in its dorsal, pelvic, and anal fin spines. Even after death its 18 venomous spines can produce wounds if not handled properly (RuizCarus et al., 2006).

\section{Conclusions}

Questions related to the role of human beings have been long asked and will continue to be the center of many ethical debacles- for we have yet to confirm that our position as highly intelligent sentient organisms requires us to assist in moderation of the evolutionary interactions of other organisms. Or perhaps the need to modulate stems from a sense of guilt or be it responsibility to correct the adverse effects of our consumptive linear economy which feeds the growing, socio-economic, political, health and environmental crises which we face. How deeply involved are we allowed to get in the movement to protect the environment? In response to modern environmental awareness trends, remediation and sustainability have become of primary focus in environmental studies. Remediation is a multidisciplinary scope of 'fix-it' strategies that aim to correct the endless consequential errs of the progress and rise of the human species and its inventions. In fact, we have found a way to include remediation and sustainability in marketing strategies which further push consumptive behavior and promote a blanketed form of conspicuous consumption.

The action of humans has had and continues to have impounding effects on the environment. On this basis we have a duty to use the growing vat of knowledge available to prevent the repeating of past incidents. Our duty to protect the environmental is a moral obligation that we must honor as (eco-centrism), in saving our environment, we also save our own existence.

The case of the invasive lionfish occurs as the result of a combination several events ultimately leading to this tremendous geographical evolution of the species. If we consider the origin, we find it as careless behavior stemming from negative displays of wealth and excess, within the context of the consumers dumping no longer wanted exotic pet fish into the sea; and ultimately those pets multiplying and successfully hijacking the host ecosystem before migrating and successfully invading ecosystems in other locations.

Despite acknowledging our moral duty to correct events such as the lionfish invasion of the Caribbean Sea and preventing the spill-over effects on marine life in this and other areas; this paper further questions our need to look more closely at the behaviors and/or events which are at the root cause of environmental issues such as this.

\section{Notes}

The authors declare no competing financial interest.

\section{Acknowledgements}

This work was supported by Professor Mao Shun of Tongji University, Shanghai, China and many other colleagues including dear friends of IESD.

\section{References}

[1] Albins MA (2013) Effects of invasive Pacific red lionfish (Pterois volitans) versus a native predator on Bahamian coral-reef fish communities. Biol Invasions 15:29-43

[2] Albins MA (2015) Invasive Pacific lionfish Pterois volitans reduce abundance and species richness of native Baha- mian coral-reef fishes. Mar Ecol Prog Ser 522:231-243

[3] Benkwitt, C. E., 2015. Non-linear effects of invasive lionfish density on native coral-reef fish communities. Biological Invasions 17: 1383-1395.

[4] Carballo-Cárdenas, E. C. 2015. Controversies and consensus on the lionfish invasion in the Western Atlantic Ocean. Ecology and Society 20(3): 24.https://oceanservice.noaa.gov/facts/lionfish-facts.ht $\mathrm{ml}$

[5] Ecology and Society 20(3): 24. http://dx.doi.org/10.5751/ES-07726-200324 Source: Ecology and Society, Vol. 20, No. 3 (Sep 2015) Schofield PJ. 2009. Geographic extent and chronology of the invasion of non- native lionfish (Pterois volitans [Linnaeus 1758] and P. miles [Bennett 1828]) in the Western North Atlantic and Caribbean Sea. Aquatic Invasions 4:473-479 DOI 10.3391/ai.2009.4.3.5.

[6] Huth, W. L., et al. (2018). "Controlling an Invasive Species through Consumption: The Case of Lionfish as 


\section{International Journal of Science and Research (IJSR) \\ ISSN: 2319-7064}

ResearchGate Impact Factor (2018): 0.28 | SJIF (2018): 7.426

an Impure Public Good." Ecological Economics 149: 74-79.

[7] Israel, J. S., et al. (2017). "Watch Out for Wild Animals: A Systematic Review of Upper Extremity Injuries Caused by Uncommon Species." Plastic and Reconstructive Surgery 140(5): 1008-1022.

[8] Johnson J, Bird CE, Johnston MA, Fogg AQ, Hogan JD. 2016. Regional genetic structure and genetic founder effects in the invasive lionfish: comparing the Gulf of Mexico, Caribbean and North Atlantic. Marine Biology 163:163-216 DOI 10.1007/s00227-016-2981-0.

[9] Mouchbahani-Constance, S., et al. (2018). "Lionfish venom elicits pain predominantly through the activation of nonpeptidergic nociceptors." Pain 159(11): 2255-2266.

[10] Morris, J.A., Jr., and P.E. Whitfield. 2009. Biology, Ecology, Control and Management of the Invasive Indo-Pacific Lionfish: An Updated Integrated
Assessment. NOAA Technical Memorandum NOS NCCOS 99. 57 pp.

[11] Rilov, G., et al. (2018). "Alien turf: Overfishing, overgrazing and invader domination in south-eastern Levant reef ecosystems." Aquatic Conservation-Marine and Freshwater Ecosystems 28(2): 351-369.

[12] Schofield, Pamela J. "Update on geographic spread of invasive lionfishes (Pterois volitans [Linnaeus, 1758] and P. miles [Bennett, 1828]) in the Western North Atlantic Ocean, Caribbean Sea and Gulf of Mexico." Aquatic Invasions 5.Supplement 1 (2010): S117-S122.

[13] Shackleton, Ross T., et al. "Social-ecological drivers and impacts of invasion-related regime shifts: Consequences for ecosystem services and human wellbeing." Environmental Science \& Policy 89 (2018): 300-314.

\section{Figures}

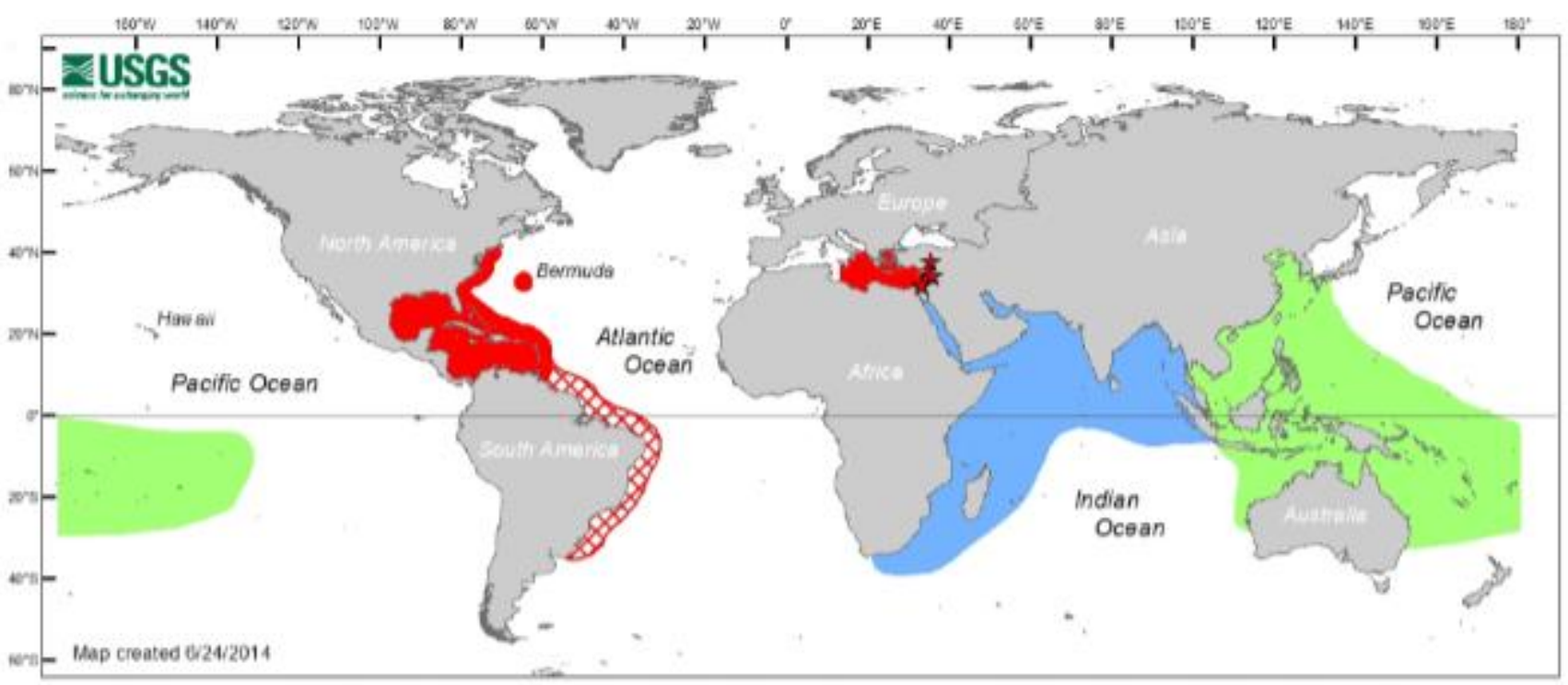

Figure 1: Native range is shown in orange on the map, South Pacific and Indian Oceans Reprinted with permission from xxx. Copyright (20xx) publishing company. Source: adapted from https://oceanservice.noaa.gov/facts/lionfish-facts.html. 


\section{International Journal of Science and Research (IJSR) \\ ISSN: 2319-7064}

ResearchGate Impact Factor (2018): 0.28 | SJIF (2018): 7.426

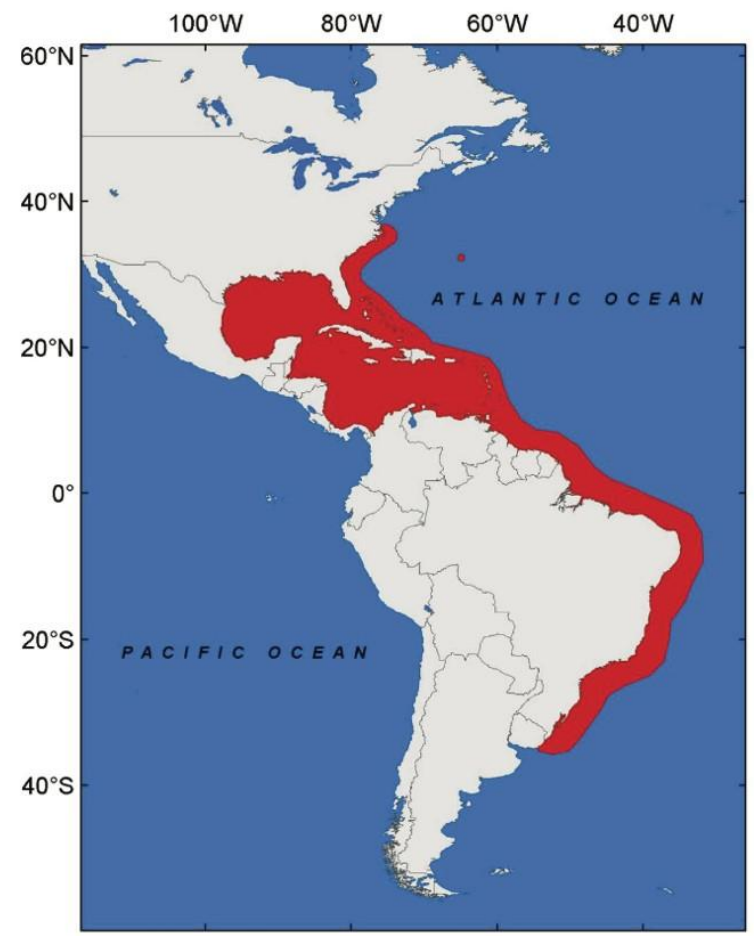

Figure 2: The US south east coast and Caribbean coastal water invasion. Add reprint permission

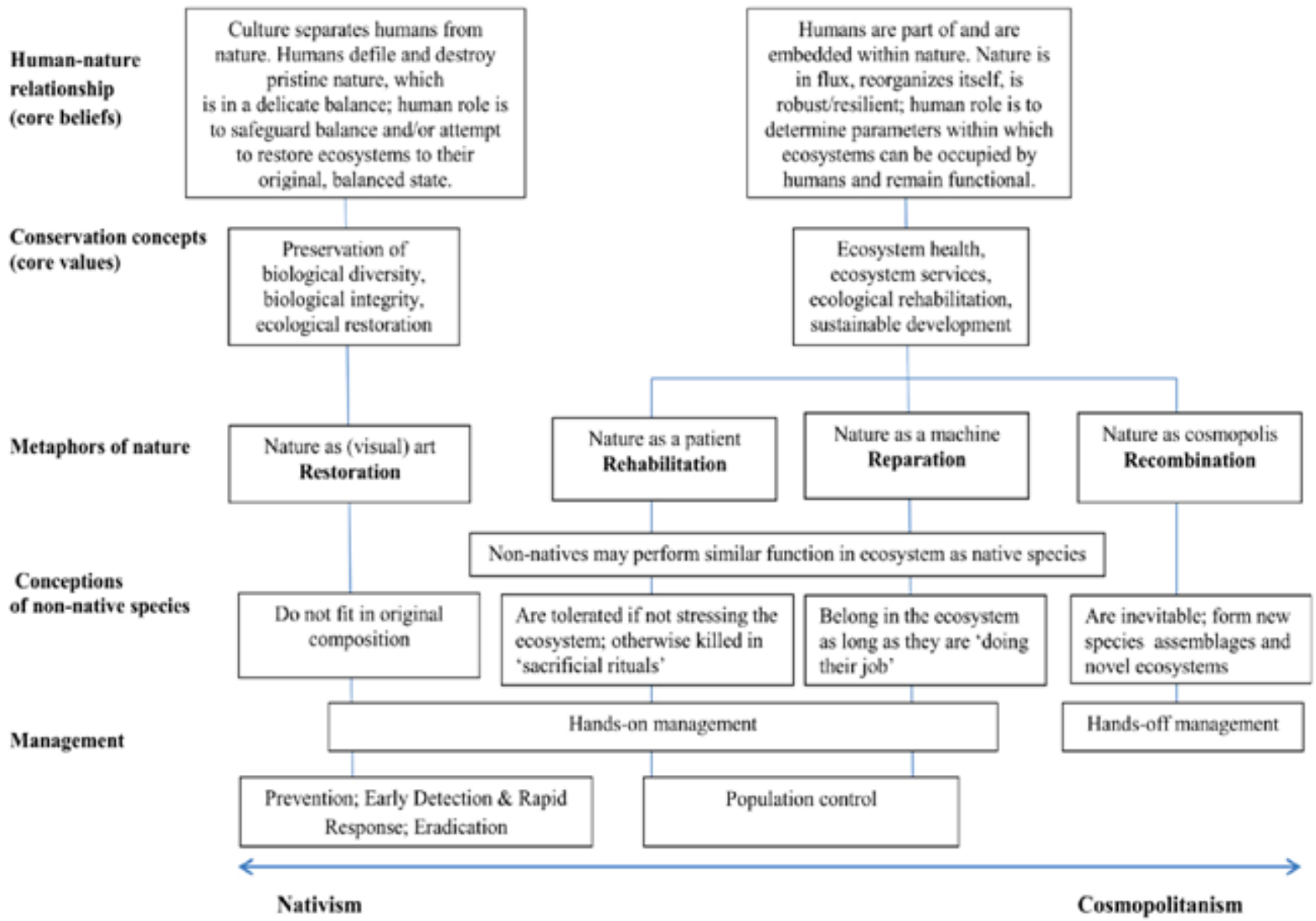

Figure 3: Conceptualizations of nature and implications for non-native species management (based on Callicott et al. 1999 and Keulartz and van der Weele 2008) in Ecology and society

Volume 8 Issue 11, November 2019 www.ijsr.net

Licensed Under Creative Commons Attribution CC BY 